Vegueta. Anuario de la Facultad de Geografía e Historia

22 (1), 2022, 217-238

eISSN: 2341-1112

https://doi.org/10.51349/veg.2022.1.12

\title{
El Catastro de Ensenada, una fuente geohistórica para el estudio del territorio de una villa castellana en el siglo XVIII
}

\author{
The Ensenada Cadastre, a Geohistorical Source for the Study of the Territory of \\ a Castilian Town in the 18th Century
}

\author{
Ricardo Hernández García ${ }^{1}$ \\ Universidad de Valladolid \\ Departamento de Fundamentos del Análisis Económico \\ e Historia e Instituciones Económicas \\ https:// orcid.org/0000-0002-1640-6676 \\ ricardo.hernandez@uva.es \\ Julio Fernández Portela*2 \\ Universidad Nacional de Educación a Distancia \\ Departamento de Geografía \\ https:/ / orcid.org/0000-0002-1677-8103 \\ jfportela@geo.uned.es
}

Recibido: 25/03/2021; Revisado: 09/09/2021; Aceptado: 26/10/2021

\begin{abstract}
Resumen
En el presente trabajo se enfatiza el hecho de utilizar una fuente documental del siglo XVIII, el Catastro de Ensenada, como herramienta de conocimiento geohistórico. Esta fuente documental permite

1 Este trabajo se ha desarrollado en el marco del Proyecto de Investigación «La estructura de la ocupación y el ingreso en el largo plazo. Redefiniendo la modernización económica y los niveles de vida en España, 1750-1975» (HAR2017-85601-C2-1-P).

2 Este trabajo se ha desarrollado en el marco del Proyecto de Investigación I+D+i PID2019-106735GBC21 del Ministerio de Ciencia e Innovación (AEI/10.13039/501100011033), titulado: «Avanzando en el conocimiento del Catastro de Ensenada y otras fuentes catastrales: nuevas perspectivas basadas en la complementariedad, la modelización y la innovación», subproyecto del proyecto coordinado Las fuentes geohistórcias, elemento para el conocimiento continuo del territorio: retos y posibilidades de futuro a través de su complementariedad (FGECCT). Grupo de Investigación Reconocido VitisUNED.
\end{abstract}

*Autor de correspondencia / Corresponding author.

Copyright: () 2022 ULPGC. Este es un artículo de acceso abierto distribuido bajo los términos de la licencia Creative Commons Atribución-NoComercial-SinDerivar (by-nc-nd) Spain 3.0. 
El Catastro de Ensenada, una fuente geohistórica para el estudio del territorio

profundizar nuestro conocimiento sobre la economía de cada localidad de la corona de Castilla. Se ha utilizado como muestra el pueblo de Cubillas de Santa Marta, en la provincia de Valladolid. Gracias a este análisis de la documentación catastral, se ha podido analizar la actividad agraria, la distribución de cultivos, y así determinar el paisaje resultante y poder compararlo con el actual.

Palabras clave: Catastro de Ensenada, geografía, agricultura, paisaje, Castilla.

\begin{abstract}
This paper reviews the use of a documentary source from the 18th century, the Ensenada Cadastre, as a tool of geohistorical study. This documentary source provides a way of furthering knowledge about the economy of each town in the crown of Castile. The town of Cubillas de Santa Marta, in the province of Valladolid, has been used as an example here. Thanks to this analysis of the cadastral documentation, it has been possible to analyse the agricultural activity and the distribution of crops, to determine the resulting landscape, and thus to be able to compare that with its current state.
\end{abstract}

Keywords: Ensenada Cadastre, Geography, Farming, Landscape, Castile.

\title{
1. INTRODUCCIÓN. EL CATASTRO DE ENSENADA EN LOS ESTUDIOS DE PAISAJE
}

El estudio del Catastro de Ensenada, una de las mejores y más fructíferas fuentes documentales del siglo XVIII para el ámbito territorial de la antigua corona de Castilla, ha permitido a numerosos investigadores en el campo de las Ciencias Sociales y las Humanidades acercarse a este periodo de la historia (MATILLA, 1947; CAMARERO, 1989, 1993, 2002a, 2002b; 2006). ${ }^{3}$ La aparente facilidad de su uso, unido a la también supuesta fácil comprensión de la caligrafía del siglo xVIII, ha animado a los geógrafos a acercarse a esta fuente documental para analizar el paisaje característico de ese periodo, así como su situación socioeconómica. El resultado de estos trabajos, a la fuerza muy dispar, ha provocado que en numerosas ocasiones su mal uso haya desvirtuado el contenido de tan preciada información (HERNÁNDEZ Y CUBERo, 2017).

La gran cantidad de datos que ofrece el Catastro de Ensenada permite, si no se desarrolla una correcta metodología, la utilización sesgada de los mismos y con ello la pérdida del contexto en el que se produjeron. Por todo ello, tratamos de mostrar al Catastro de Ensenada como una fuente geohistórica completa y homogénea para conocer cuál era la situación de la sociedad, la economía y el paisaje castellano a mediados del siglo XVIII. En definitiva, una fuente empleada por historiadores y geógrafos para realizar estudios de paisaje, tanto rural como urbano, y poder analizar, entender y reinterpretar la evolución de un territorio en diferentes momentos temporales entre el siglo XVIII y la actualidad (PILLET, 2007; MuÑoz, 2010; GarCía et al., 2017; ValLina y KonyUSHIKHINA, 2017; Vidal, 2018). Además de los estudios de paisaje, el Catastro de Ensenada se convierte en una fuente estratégica como punto de partida para conocer la estructura de la población del territorio en un momento dado (CAMARERO et al., 2018) y poder afrontar los estudios de demografía actual con una base histórica sólida. Una situación que preocupa, a los investigadores (LÓPEZ, 2007; Molina, 2018) y a las

3 Igualmente, todas las de la colección Alcabala del Viento o las aparecidas en la revista CT Catastro. 
administraciones públicas ${ }^{4}$, con un incremento notable de los trabajos científicos en este campo, así como un avance importante en el desarrollo de la legislación y la documentación oficial hasta tal punto que se ha creado un Ministerio para la Transición Ecológica y el Reto Demográfico en el Gobierno de España, y en Castilla León, se ha puesto en marcha la aprobación de una Ley de Dinamización Demográfica de la Comunidad de Castilla y León.

La renovación académica e investigadora que supuso la Escuela de los Annales en Europa a partir de la década de 1930, generó una nueva forma de hacer historia más allá de la de los hechos políticos y los conflictos bélicos (BLOCH, 1952; Febvre, 1970; Braudel, 1953 y 1968; Le Roy, 1973). En el caso español, esta nueva corriente impulsó el estudio del mundo rural como algo fundamental para comprender la evolución histórica de un territorio. No sólo la política y los hechos militares transformaban la historia, sino que esa transformación dependía mucho más de los comportamientos colectivos y anónimos del conjunto de la población, y sobre todo de su relación entre ésta y el entorno en el que desarrollaba su actividad, es decir, el paisaje que le rodeaba. Más allá de análisis de hechos puntuales, cobró fuerza el estudio de grandes espacios a lo largo de un amplio periodo cronológico que estaban ligados por lazos geográficos que condicionaban, aunque no determinaban, su economía (VIDAL, 1913; OrelLA, 1995). De repente el análisis provincial cobraba importancia, y sobre todo, dentro del provincial, el comarcal presentaba una serie de ventajas geográficas que posibilitaban un análisis completo y multifactorial. Buena muestra de ello son diferentes trabajos, ya clásicos, que se desarrollaron sobre estos espacios en el ámbito castellano (CABO, 1955 y 1956; García, 1963; Ortega, 1969; Huetz, 1967; Bennassar, 1967; Crespo, 1968; BRUMONT, 1977; MARCos, 1985; GARCíA, 1986), así como investigaciones más recientes (CUBERO Y HERNÁNDEZ, 2017).

En el presente trabajo se tratarán de alcanzar los siguientes objetivos: en primer lugar, evaluar la viabilidad de efectuar estudios geohistóricos para comprender la realidad socioeconómica de una localidad castellana a mediados del siglo XVIII, y que puede servir como modelo para la inmensa mayoría de municipios de la corona de Castilla, que basaba su desarrollo económico en la economía agraria, y por lo tanto estaba muy condicionada por el paisaje y el medio físico; en segundo lugar, explorar una fuente documental como el Catastro de Ensenada, válido para prácticamente todas las localidades de la corona de Castilla, como fuente de estudio geohistórica; y en tercer lugar, diseñar una estrategia eficaz de trabajo para aprovechar los recursos que ofrece el Catastro de Ensenada a través de todos sus estratos documentales.

En primer lugar describiremos el territorio sobre el que vamos a desarrollar la investigación y lo centraremos espacial y cronológicamente; después analizaremos en detalle la principal fuente documental utilizada -las Respuestas Generales del Catastro de Ensenada-, así como la metodología utilizada; finalmente se estudian todas las actividades económicas que aparecen en la documentación, así como su relación con el paisaje de la época y del presente.

4 A escala nacional: Real Decreto 40/2017, de 27 de enero, por el que se crea el Comisionado del Gobierno frente al Reto Demográfico y se regula su régimen de funcionamiento. Fuente: https:// www.boe.es/buscar/doc.php?id=BOE-A-2017-915. ; A escala regional: Agenda para la población de Castilla y León 2010-2020 (versión inicial 44/2010). Modificada posteriormente por Acuerdo 55/2014 y Acuerdo 44/2017. Fuente: https://www.jcyl.es/web/es/agendapoblacion/agenda-para-poblacion/ agenda-poblacion-2010-2020.html 


\section{2. ÁREA DE ESTUDIO}

El enfoque metodológico que acabamos de exponer pone el foco en la geografía y en la historia económica para rescatar las coordenadas fundamentales de amplios territorios, como el que vamos a utilizar en este trabajo. Para ello, centraremos nuestra atención general en la actual comarca de la Campiña del Pisuerga, en la provincia de Valladolid, formada por 16 localidades, y en concreto en una de ellas, Cubillas de Santa Marta. A mediados del siglo XVIII, este municipio formaba parte de una entidad denominada Valle de Trigueros, que englobaba a las localidades de Trigueros del Valle, Quintanilla de Trigueros, Corcos y la propia Cubillas (más el despoblado de Valenoso y la Granja de Canaleja) (Figura $1)$.
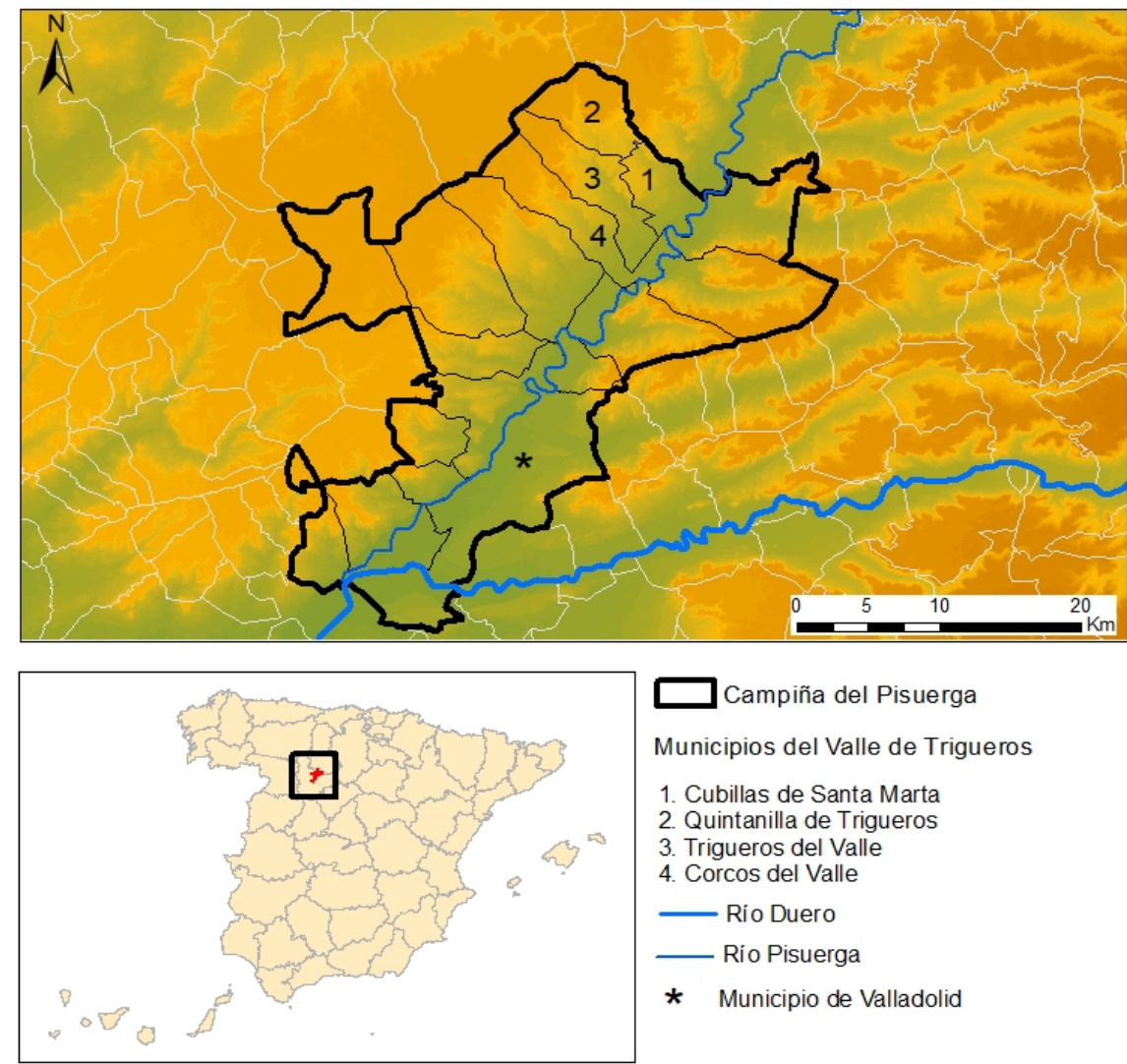

Campiña del Pisuerga

Municipios del Valle de Trigueros

1. Cubillas de Santa Marta

2. Quintanilla de Trigueros

3. Trigueros del Valle

4. Corcos del Valle

- Río Duero

- Rio Pisuerga

* Municipio de Valladolid

Figura 1. Área de estudio. Cubillas de Santa Marta en la Campiña del Pisuerga. Fuente: Elaboración propia.

Estas cuatro villas compartían el uso y disfrute de tierras y pastos que eran de uso comunal («consuniego»), elemento éste que nos retrotrae a una época pretérita en la que compartiesen además de esas tierras otros elementos como son la justicia 
o la administración local. De hecho, todavía a mediados del siglo XVIII estas cuatro eran localidades de señorío, perteneciendo éste, así como algún derecho anejo, a Joaquín José de Luján Robles y Silva, a la sazón III conde de Castroponce.

En las Respuestas Generales, en concreto en la número 3, Qué territorio ocupa el término, cuánto de levante a poniente y del norte al sur, y cuánto de circunferencia, por horas, y leguas, qué linderos o confrontaciones; y qué figura tiene, poniéndola al margen, se específica, para Cubillas de Santa Marta, lo siguiente:

...confronta (el Valle) por Levante con el río Pisuerga y con parte del término de la villa de Dueñas; por el Norte con el monte de dicha villa y con el término de la de Santa Cecilia y monte de la Torre de Mormojón; por el Poniente con la dehesa del conde de la Gomera y monte de la villa de Ampudia; y por Sur con los términos de la villa de Cigales y Cabezón, y del monasterio que se intitula de Nuestra Señora de Palazuelos, Orden de San Bernardo (Figura 2)..$^{5}$

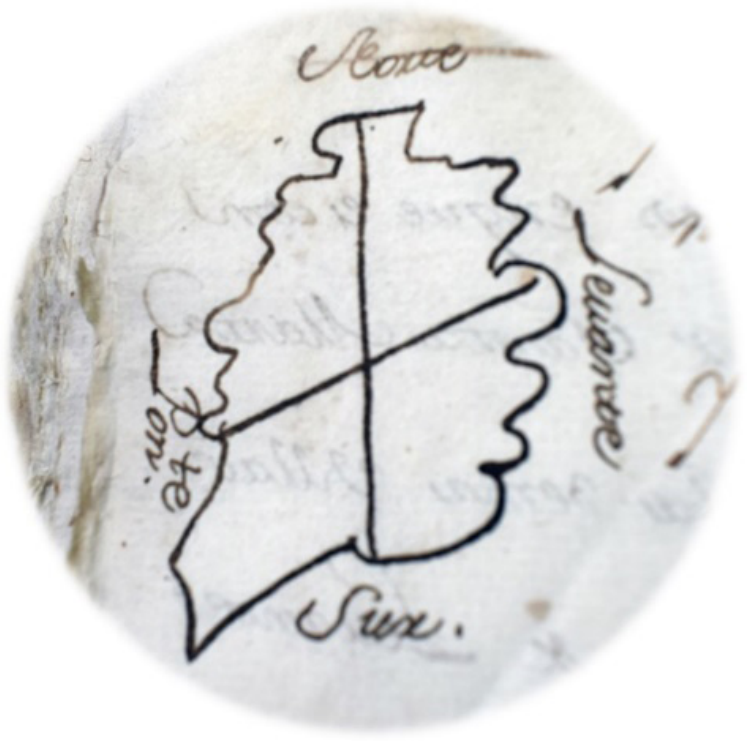

Figura 2.Término municipal de Cubillas con los cuatro aires marcados.

Fuente: Archivo Municipal de Cubillas de Santa Marta (AMC), Libro de Haciendas de Cubillas.

Además de los límites inmediatos del término municipal de Cubillas de Santa Marta, hay que indicar que esta localidad forma parte del Bajo Valle del Pisuerga entre los páramos del Cerrato y los montes Torozos (Figura 1), con una altitud

5 Respuestas General del Catastro de Ensenada en Cubillas de Santa Marta. Fuente: Portal de Archivos Españoles (PARES) http://pares.mcu.es/Catastro/servlets/ServletController?ini=0\&accion=0\&map as $=0 \&$ tipo $=0$ Respecto a la cartografía en el Catastro de Ensenada es imprescindible consultar los trabajos de Camarero (1998) y López y Manso (2006). 
comprendida entre los 700 y los 800 metros sobre el nivel del mar, y atraviesan su término municipal el Canal de Castilla, un cordel de la Cañada Real Leonesa Oriental (en concreto el Ramal Dueñas-Olmedo), la línea de ferrocarril MadridHendaya y la Autovía A-62, en definitiva, un espacio geográfico bien comunicado a lo largo de la historia.

Cuenta con un sistema de terrazas escalonadas disimétricas creadas por el río Pisuerga de origen periglaciar (OMO y Portero, 1982; Serrano et al., 2010), diferenciando en el sector de Cubillas hasta 4 niveles de terrazas entre los 10 y los 60 metros sobre el cauce actual del río. La planicie y la homogeneidad del territorio conforman un paisaje de llanura, de campos abiertos, sin límites, una monotonía que tan solo se rompe con la presencia de las cuestas de los páramos. El clima característico de este espacio es mediterráneo de interior, con una temperatura media anual de $12,04^{\circ} \mathrm{C}$ siendo la media mínima mensual en el mes de enero con $3,3^{\circ} \mathrm{C}$ y la media máxima mensual en julio con $21^{\circ} \mathrm{C}$. Sin embargo, en invierno estas temperaturas pueden descender algunos días hasta los $-4^{\circ} \mathrm{C}$ y, en verano, pueden superar los $37^{\circ}$. Estos contrastes de temperatura originan oscilaciones térmicas anuales medias de alrededor de $18^{\circ} \mathrm{C}$ y máximas de $40^{\circ} \mathrm{C}$. Respecto a las precipitaciones, el total anual es de 435 milímetros con máximos equinocciales en primavera y otoño, y mínimos en verano presentando una aridez estival de tres meses.

Este emplazamiento, junto con el clima, condiciona la actividad agraria basada en el cultivo del cereal y el viñedo (GARCía, 1963; Molinero, 2012; FernándeZ, 2018), y que ha sido y es la base económica de la mayoría de los municipios de Castilla y León. Esto les otorga unas singularidades capaces de crear unos paisajes agrarios reconocibles por sus características, y reconocidos por su población, (NoGUÉ, 2017).

\section{FUENTES Y METODOLOGÍA}

Atendiendo a lo que señala CAMARERO (2002a: 113):

...Catastro de Ensenada es la denominación que se da a la averiguación llevada a cabo en los territorios de la Corona de Castilla para conocer, registrar y evaluar los bienes, rentas y cargas de los que fuesen titulares sus moradores, debiendo quedar éstos también formalmente registrados, así como sus familias, criados y dependientes.

El desarrollo de todas estas operaciones se dilató desde abril de 1750 al mismo mes de 1756 y el objetivo fundamental que sustenta la puesta en marcha de un catastro es la de conocer «todo de todos», como ya en su momento señaló el propio Ensenada (CAMARERO, 2002b). Para ello, era imprescindible tener toda la información necesaria para cambiar el sistema impositivo vigente, y conseguir que la Hacienda percibiese mayores ingresos. También se pretendía simplificar la maraña de impuestos existentes, hacer extensivo el pago de impuestos a la nobleza y el clero, y finalmente, imponer un sistema basado en la fiscalidad directa con base en la riqueza de cada individuo, y no en la indirecta, como era norma común hasta ese momento, basada en el consumo. 
El proceso de elaboración de la operación catastral en cada localidad perteneciente a la corona de Castilla, salvo Canarias, Provincias Vascas y el Reino Foral de Navarra, que poseían fiscalidad propia, comenzaba con el envío a cada localidad de una carta anunciando la próxima llegada de una audiencia para desarrollar dicha operación (BÉTHENCOURT, 2004). Tras su llegada a la localidad, los vecinos elaboraban sus declaraciones también conocidas como memoriales (Figura 3). Estos eran las relaciones personales que aportaba cada vecino o institución, referentes a los miembros de su familia. Incluían sus nombres, edades, ocupaciones, así como la descripción del oficio u oficios del cabeza de casa, las tierras de cultivo y sus calidades, casas, animales de esquilmo, así como las rentas de tierras tomadas a eclesiásticos y las cargas de censos y memorias fundadas sobre sus bienes.

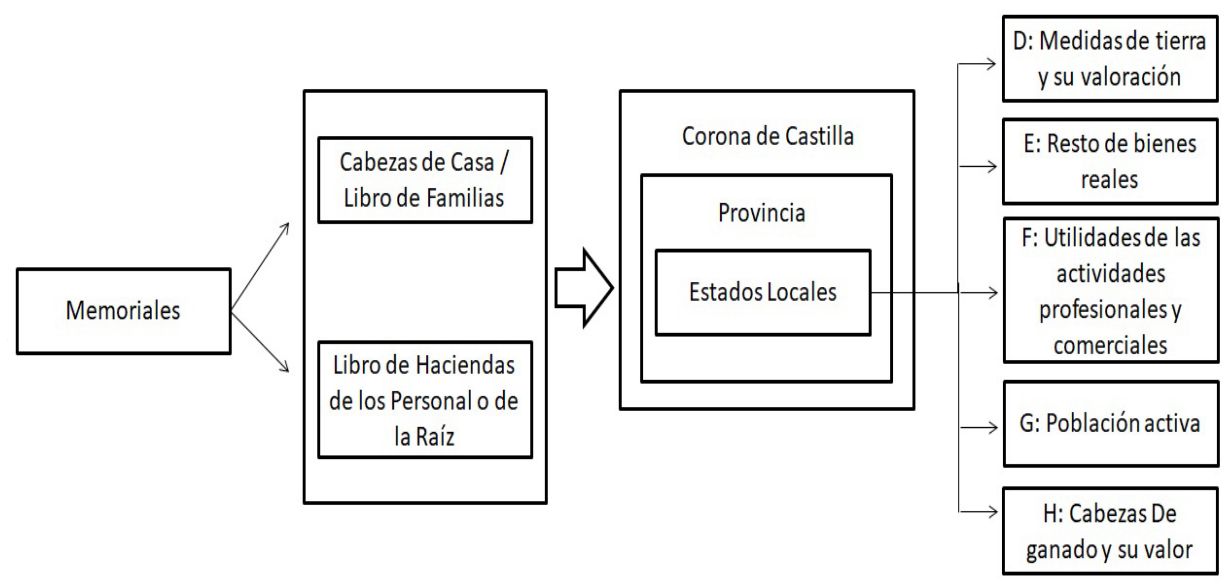

Figura 3. Esquema de la operación catastral de la Única Contribución.

Fuente: Elaboración propia.

El siguiente paso consistía en sumar todos estos datos en lo que se denominaba Estados Locales, para después agregarlos a toda la provincia y finalmente a toda la corona de Castilla. Estos Estados eran cinco, uno, el de la Letra D, correspondía a las medidas de tierras y su valoración; el de la Letra E recogía el resto de bienes reales; el de la Letra F incluía las utilidades de las actividades profesionales y comerciales; el de la Letra $\mathrm{G}$ agrupaba la población activa incluida en el impuesto de lo personal; y finalmente el de la Letra $\mathrm{H}$ señalaba las cabezas de ganado existentes y su valor (Figura 3). En definitiva, una radiografía bastante completa de la situación socioeconómica y del paisaje rural de toda Castilla.

A pesar de toda esta ingente cantidad de trabajo, y pese a todos los cálculos efectuados, la Única Contribución nunca llegó a implantarse ante la oposición de sus principales detractores, la nobleza y el clero, es decir, los estamentos privilegiados, que no sólo consiguieron la paralización de la reforma fiscal, sino que también consiguieron la caída en desgracia del propio Ensenada (RoDRíGuEZ, 1878; GómEZ, 2017).

En este trabajo se utilizarán diferentes niveles documentales: las Respuestas 
Generales, el Libro de Cabezas de Casa, el Libro de Haciendas, y los Estados Generales. ${ }^{6}$ Las Respuestas Generales son las respuestas de cada municipio a cuarenta preguntas relativas a diferentes aspectos como su pertenencia jurisdiccional al realengo o al señorío, la producción agrícola, la tenencia de animales y su esquilmo o aprovechamiento, los diferentes oficios y la utilidad o salarios por categoría profesional, los bienes de propios y del común, así como los ingresos y gastos de la hacienda municipal, y por último, información sobre el estamento eclesiástico y las instituciones de beneficencia. De todas estas preguntas nosotros utilizaremos fundamentalmente las referentes a los datos económicos, prestando especial atención a aquellas preguntas que aporten información sobre la distribución de los diferentes cultivos y la composición del paisaje. Del mismo modo, utilizaremos la información facilitada en el estrato documental superior y más depurado, los Estados Generales, donde se agrupa numéricamente toda la información obtenida. Además de las Respuestas Generales y los Estados Generales, que nos van a aportar una visión amplia y general de la realidad socioeconómica de la localidad, utilizaremos el Libro de Cabezas de Casa, donde aparecen todos sus habitantes, y el Libro de Haciendas, donde se recoge la información de cada vecino relativa a sus bienes imputables a efectos fiscales. De esta manera podemos descender a un conocimiento mucho más preciso y detallado que con la anterior documentación, y de esta forma, distinguir a los diferentes vecinos en función a sus bienes (HeRNÁndEZ y CuBERo, 2017).

\section{RESULTADOS Y DISCUSIÓN}

\subsection{Población y territorio en Cubillas de Santa Marta: un municipio con poca población y escasa extensión superficial}

A mediados del siglo xviII la villa era una localidad de señorío perteneciente al conde de Castroponce, señor de las localidades que junto a Cubillas conformaban el Valle de Trigueros. Por razón de su señorío percibía el impuesto de la martiniega, de origen medieval, consistente en una pequeña cantidad, 66 reales de vellón (rs.) anuales. También le pertenecían las Tercias Reales y la percepción de la alcabala, si bien ambos impuestos los tenía cedidos a favor de la hacienda municipal, con el propósito de favorecer a los vecinos de Cubillas en el pago de las contribuciones reales. A estos efectos, el Catastro también ofrece información demográfica, así, en la respuesta a la pregunta 27 señalaban que, «...esta villa está sumamente cargada no sólo en el Servicio Ordinario y Extraordinario, sino también en los demás efectos en que contribuye a Su Majestad por la suma decadencia, imposibilidad y pobreza a que ha venido este pueblo». Tal vez el mejor indicador para calibrar esa supuesta decadencia sea conocer algún dato referente a la evolución de la población. Sabemos que en el censo del año 1591 Cubillas contaba con unos

6 Las Respuestas Generales se encuentran en el Archivo General de Simancas (AGS), Dirección General de Rentas (DGR), $1^{\text {a }}$ remesa, libro 476; el Libro de Haciendas o de lo Real, y el Libro de Cabezas de Casa, en el AMC; y los Estados Generales, en el Archivo Histórico Nacional (AHN), sección fondos contemporáneos, Ministerio de Hacienda, libros 7.472 a 7.475. 
200 habitantes, mientras que según los datos del Libro de Cabezas de Casa del Catastro de 1751 , esta cifra se había reducido a 171 habitantes. ${ }^{7}$ No parece que esta situación fuese puntual, ya que en la respuesta a la pregunta 22 de las Generales, señalaban que había un total de 35 casas habitadas, 11 cerradas «...por falta de vecinos que las habiten», y 10 arruinadas «...que sólo han quedado los vestigios de haberlo sido...».

La tercera pregunta requería información sobre el territorio que ocupaba el término, señalando los límites con el resto de pueblos circundantes. No obstante, la información que ofrece es la relativa al conjunto del Valle de Trigueros. ¿Quiere esto decir que no podemos saber cuánto medía el término municipal de Cubillas de Santa Marta a mediados del siglo xvIII? No necesariamente. Gracias a los datos recopilados en el Libro de Haciendas se puede reconstruir cuál era ese espacio sumando todas las parcelas de tierra declaradas por los vecinos de Cubillas, las de los forasteros que poseían tierras en el término, las propiedades del concejo, y los bienes propiedad de miembros del estamento eclesiástico. Lamentablemente la cuantía de estos últimos bienes no podemos conocerla, ya que ha desaparecido esta documentación. De todas formas, como se verá, la aproximación que podemos hacer a mediados del siglo XVIII se acerca bastante a la superficie que tiene el municipio en la actualidad.

La suma de todas las parcelas reflejadas en el Libro de Haciendas alcanza las 2.024,5 hectáreas, consignando en esa cifra todas las tierras del término. Estas tierras se dividen en tres grandes apartados, en primer lugar, las tierras propiedad de vecinos de Cubillas, que sumaban 586,8 hectáreas (el 29\% del total), en segundo lugar las tierras de forasteros, que alcanzaban las 300,4 hectáreas (15\%), y en tercer lugar la cuarta parte que le pertenecía a Cubillas de Santa Marta como integrante del Valle de Trigueros, que sumaba 1.137,3 hectáreas (56\%). Teniendo en cuenta que el término municipal actualmente se extiende a través de 2.355 hectáreas, ${ }^{8}$ faltan en nuestro recuento 330,5 hectáreas, que bien podrían ser las que aportase el estamento eclesiástico en sus relaciones y que lamentablemente han desaparecido.

\subsection{La agricultura como principal soporte económico: el dominio del cultivo del cereal y la discreta presencia del viñedo}

Desde la pregunta 4 a la 14 las Respuestas Generales nos ofrecen la información más relevante de todas, la de la actividad agraria. El Interrogatorio comienza con una pregunta sobre los tipos de tierras que se encuentran en el término municipal, siendo éstas de secano de sembradura, viñas, pasto, páramos y matorrales. Tanto las tierras de sembradura como las dedicadas a viñedo las califican de tres calidades, «...buena, mediana e inferior», produciendo las de sembradura un año cada dos (año y vez), mientras que las viñas lo hacían anualmente. Por su parte, las tierras denominadas herrenes, que era un reducido número de tierras

7 Censo 1986: 427.

8 https://www.ayuntamiento-espana.es/ayuntamiento-cubillas-de-santa-marta.html 
próximas al casco urbano, se sembraban de cebada para proporcionar forraje a los animales de labor, produciendo dos años seguidos y descansando el tercero. Además de las tierras de cultivo existían otras destinadas a pasto y otras que eran infructíferas, bien por desidia -abandono-, bien por su propia naturaleza. Por lo demás, no consignan la existencia de ningún plantío de árboles frutales en el término, lógica consecuencia, como en otras localidades cercanas, de la «secura del terreno» (PEÑA, 1987: 56).

Otro tema fundamental para visualizar en la actualidad el paisaje de mediados del siglo XVIII, es el referente a las medidas de superficie utilizadas en el pueblo, así como el rendimiento obtenido en cada tipo y calidad de tierra. Como indican en la respuesta a la pregunta número 9, la medida de tierra utilizada para las tierras de secano era la obrada de seis cuartas, siendo cada una de ellas de 100 estadales. Por su parte, para los viñedos utilizaban la obrada, compuesta por 3 aranzadas, y cada una de ellas de dos cuartas de cien estadales cada una, que albergaban 250 cepas. Según estos datos, y teniendo en cuenta que la vara castellana medía 0,835905 metros, sabemos que la obrada equivalía a $5.382 \mathrm{~m}^{2}$, o lo que es igual, 0,5382 Ha y cada cuarta 0,0897 Ha. Del mismo modo, la aranzada equivalía a 1.794 $\mathrm{m}^{2}$ o 0,1794 Ha. Gracias a estos datos podemos calcular qué proporción había de cada tipo de tierra en función de su uso, como se muestra en el cuadro 1.

CuAdro 1

Usos de la tierra y extensión en hectáreas en Cubillas de Santa Marta en 1751

\begin{tabular}{|c|c|c|c|c|c|c|c|c|}
\hline & TOTAL & $\%$ & $\begin{array}{c}\text { Vecinos } \\
\text { Cubillas }\end{array}$ & $\%$ & Forasteros & $\%$ & $\begin{array}{c}\text { 1/4 Valle } \\
\text { Trigueros }\end{array}$ & $\%$ \\
\hline $\begin{array}{c}\text { Tierras de } \\
\text { sembradura }\end{array}$ & 661 & 30 & 326,1 & 49 & 277,3 & 42 & 57,6 & 8,7 \\
\hline Viñas & 71,1 & 3,2 & 40 & 56 & 22 & 31 & 9 & 13 \\
\hline Herrenes & 2,5 & 0,2 & 1,7 & 68 & 0,8 & 32 & & \\
\hline Eras & 1,6 & 0,1 & 1,3 & 81 & 0,3 & 19 & & \\
\hline $\begin{array}{c}\text { Pastos + } \\
\text { Yermas }\end{array}$ & $1.288,3$ & 58,5 & 217,6 & 17 & & & $1.070,7$ & 83 \\
\hline TOTAL & $\mathbf{2 . 0 2 4 , 5}$ & $\mathbf{1 0 0}$ & $\mathbf{5 8 6 , 8}$ & $\mathbf{2 9}$ & $\mathbf{3 0 0 , 4}$ & $\mathbf{1 5}$ & $\mathbf{1 . 1 3 7 , 3}$ & $\mathbf{5 6}$ \\
\hline
\end{tabular}

Fuente: Elaboración propia a partir del Libro de Haciendas.

Si tenemos en cuenta todas las tierras, la mayor extensión es la dedicada a pastos y tierras yermas con el $58,5 \%$, mientras que las tierras de sembradura suman el 30\%, y los viñedos sólo llegan al 3,2\%. Estos datos concuerdan con la escasa densidad demográfica del corazón de Castilla a mediados del siglo XVIII, y en particular con la despoblación de Cubillas ya señalada ante la falta de labranzas y la existencia de tierras baldías. No obstante, si nos centramos al 
hacer el cálculo sólo en las tierras dedicadas a la producción de cereales y vino, es decir, tierras de sembradura y viñedo, las primeras abarcarían el 90,3\% frente al 9,7\% del viñedo, cifras acordes a buena parte de los pueblos de su entorno como San Martín de Valvení con el 4,8\%, Santovenia de Pisuerga 8\%, Cabezón $8,8 \%$, Fuensaldaña 4,8\% y Mucientes 7,6\%. ${ }^{9}$ Es este un elemento del paisaje que ha cambiado en la actualidad sustancialmente a favor del viñedo, ya que como reflejan las cifras del año 2017, el 68,88\% de la superficie cultivada en Cubillas se destinaba a los herbáceos y el 31,12\% -más del triple de la cifra de 1751- a viñedo, siendo el municipio de toda la D.O. Cigales con mayor porcentaje de cultivo de vides, casi duplicando el valor de la localidad de Cigales que era del $16,21 \% .{ }^{10}$ Esta fuerte vinculación a la producción de cereal se justifica plenamente por los condicionantes climáticos que, en buena medida, impiden otro tipo de cultivo, máxime cuando además tenemos en el siglo XVIII un tipo de propiedad de la tierra que tiende a la concentración en pocas manos, y por ello maximiza sus resultados en los cultivos extensivos (GARCíA, 1963 y 1986).

También puede ser interesante establecer este análisis de la propiedad de la tierra en función del cultivo a que ésta se dedicaba. De este modo, se puede ver cómo los vecinos de Cubillas eran los principales propietarios en las tierras de sembradura de secano, el viñedo y en las eras. Por su parte, los forasteros de la villa tenían un nada despreciable $40 \%$ de las tierras de sembradura y $31 \%$ de los viñedos. Por último, la cuarta parte de tierras que le correspondía a Cubillas por su pertenencia al Valle de Trigueros, de manera abrumadora eran destinadas a pasto para el ganado y a tierras yermas, ya que como se ha visto, no había necesidad de roturar dichos terrenos debido a la escasa presión demográfica existente.

¿Podemos saber qué productos se cultivaban en estas tierras a mediados del siglo XVIII? La respuesta a la pregunta 11 indica que en Cubillas había anualmente producción de trigo, cebada, centeno, avena y vino, si bien otra pregunta, la 16, añadía una corta producción de lentejas. En definitiva, productos agrarios que se adaptaban perfectamente a los exigentes condicionantes climáticos antes reseñados. Si bien no disponemos de datos sobre la producción anual, sí que podemos establecer una aproximación gracias a los datos que aporta el Catastro sobre el pago del diezmo. Sabiendo que se pagaba una décima parte de la producción agraria en bruto, podemos aproximarnos a la cifra exacta entregada anualmente. Atendiendo a esa cifra del pago del diezmo consignada en las Respuestas Generales, sabemos que la producción anual media de trigo a mediados del siglo XVIII era de unas 255 cargas (56.100 litros), la de cebada de 269 cargas (59.180 litros), la de centeno de 29 cargas (6.380 litros), la de avena de 54 cargas (11.880 litros), la de lentejas de 6 cargas (1.320 litros), y finalmente la de vino de 449,28 hectolitros o 44.928 litros, cifra ésta muy alejada de los 20.655 hectolitros producidos en la cosecha del año 2019.11 Como se puede observar, la producción fundamental era la de cebada y trigo, mientras que el centeno y la

\footnotetext{
9 Datos obtenidos de las Respuestas Generales de las respectivas localidades. AGS, DGR, $1^{\text {a }}$ remesa, libros 646, 659 y 661. Lo mismo sucedía en la Tierra de Campos vallisoletana (PeÑA, 1987: 76; HernándeZ Y CUBERo, 2017: 406).

10https://agriculturaganaderia.jcyl.es/web/es/estadistica-informacion-agraria/avancessuperficies-produc ciones. html

11 El diezmo reflejado es la media del periodo 1746-1750 -cinco años anteriores a la operación catastral-, para evitar de este modo que uno o dos años de crisis agraria desvirtuasen la cifra tomada como referencia.
} 
avena, y sobre todo las lentejas, tenían una presencia prácticamente circunstancial. La producción de vino también era escasa en ese momento si la comparamos con la de localidades limítrofes como Cigales (20.000 hectolitros), Valoria la Buena (4.000 hectolitros), Trigueros del Valle (1.611,2 hectolitros), Corcos (1.158,4 hectolitros) o Dueñas (13.600 hectolitros)..$^{12}$

Por último de cara a evaluar la producción agraria, el Catastro también ofrece información referente a los precios medios anuales, así, establecen el precio de la fanega de trigo en 11 rs., la de cebada en 5,5 rs., la de centeno en 8 rs., y la cántara de vino en 3,5 rs., es decir, unos precios muy parecidos a los establecidos en buena parte de la zona circundante a Cubillas. A estos efectos, por situar un poco el valor de estos precios, el jornal diario de un jornalero, el día que trabajaba, oscilaba entre los 1,5 y 2 rs., lo que da idea del escaso poder adquisitivo de estos trabajadores, así como de su precario nivel de vida.

Una vez que conocemos qué usos se daba a la tierra y cuáles eran los productos obtenidos en Cubillas, cabe preguntarse cómo era la calidad de las tierras del término municipal (Cuadro 2). Sin lugar a dudas este dato nos permitirá interpretar mejor si la producción agrícola estaba condicionada por el mercado o por los condicionantes geográficos como la climatología o la riqueza de los suelos de cultivo.

El principal grupo de tierras de sembradura, es decir, las tierras de cereal, eran de pobre calidad, aquí identificadas como T3. Casi el 70\% del total -67,6\%eran de esta calidad, mientras que las tierras de buena calidad -T1- no llegaban al $8 \%$. Indudablemente esto va a condicionar el hecho de que los rendimientos que se obtengan del cultivo de estas tierras sean muy pobres. Este análisis lo podemos hacer todavía más preciso gracias a los datos que ofrece la pregunta número 9 referentes a la cantidad de simiente que se siembra en cada tipo y calidad de tierra, así como a los datos de la pregunta 12, en los que se consigna la cantidad de frutos que produce cada tipo de tierra y calidad. Gracias a la combinación de estos dos datos podemos calcular los rendimientos de la producción agraria a mediados del siglo XVIII.

CUADRO 2

Hectáreas de tierras en función de su calidad y propietario

\begin{tabular}{|c|c|c|c|c|c|c|}
\hline & T1 & T2 & T3 & V1 & V2 & V3 \\
\hline Vecinos & 28,6 & 71,9 & 225,6 & 8,6 & 15,8 & 15,6 \\
\hline Forasteros & 19,5 & 62,7 & 195 & 3,3 & 9,3 & 9,5 \\
\hline $\begin{array}{c}\text { 1/4 Valle de } \\
\text { Trigueros }\end{array}$ & $\mathbf{1 , 3}$ & 30,2 & 26,2 & 1,6 & 7,4 & \\
\hline TOTAL & $\mathbf{4 9 , 4}$ & $\mathbf{1 6 4 , 8}$ & $\mathbf{4 4 6 , 8}$ & $\mathbf{1 3 , 5}$ & $\mathbf{3 2 , 5}$ & $\mathbf{2 5 , 1}$ \\
\hline
\end{tabular}

$\mathrm{T}=$ Tierras de sembradura de secano; $\mathrm{V}=$ Tierras de viñedo; 1,2 y 3 = Primera, segunda y tercera calidad. Fuente: Elaboración propia a partir del Libro de Haciendas.

12 La referencia de Cigales está tomada de Huetz (1967: 230), y las del resto de localidades, de sus respectivas Respuestas Generales, en AGS, DGR, $1^{a}$ remesa, libros 659, 480, 476 y 477. 
Mientras que las tierras de sembradura de buena calidad tenían unos rendimientos de 2,8 granos recogidos por cada uno sembrado de trigo, y de 4,8 en el caso de la cebada, en las tierras de segunda calidad o medianas -T2-, estos rendimientos son de 2,5 para el trigo y de 5 para la cebada. Por último, en las tierras de peor calidad, que eran la mayoría, su pobre rendimiento condicionaba el que hubiese que sembrar cereal poco exigente con el suelo y que se adaptase bien a esa escasez de recursos, como la avena y sobre todo el centeno, cultivos que habían sustituido al trigo y a la cebada debido a su mejor adaptación a esos pobres suelos. En este sentido, es pertinente recordar a Jovellanos, quien en uno de sus viajes, a su paso por la vecina localidad de Dueñas, señalaba con asombro al referirse a los escasos rendimientos ofrecidos por las tierras sembradas de trigo: «...en las eras pregunto el rendimiento del trigo en la presente cosecha, y me dicen que a carga y media por media, esto es, a tres por simiente, cosa para mí admirable» (Jovellanos, 1994: 227). ${ }^{13}$ A estos efectos, otro nivel de la documentación catastral, los Estados Generales, en concreto el de la Letra D que recoge la suma de todas las parcelas de tierra agrupadas por su diferente valor o utilidad, indica que de las 19.928 parcelas consignadas para los bienes propiedad de seglares, el 63,4\% sólo tenían «producto anual» de 0,25 rs., o lo que es lo mismo, eran tierras de escasa calidad con rendimientos muy pobres.

Si en vez de las tierras de sembradura analizamos las plantadas de viñedo, se observa que la calidad de los mismos está más repartida entre los de mediana y mala calidad, siendo los primeros el 45,7\% del total, y los segundos el 35,3\%. Por su parte, tan sólo encontramos un 19\% de viñedos considerados, en función al volumen de su producción, como de buena calidad. En definitiva, el viñedo que existía en Cubillas de Santa Marta a mediados del siglo XVIII era de inferior calidad que las tierras dedicadas al cultivo de cereal. En el caso de los propietarios del viñedo sí que se percibe una relativa concentración en manos de propietarios ajenos a los vecinos de Cubillas, ya que de las viñas de buena calidad los propietarios forasteros poseen el 36\%, y de mediana calidad el 28,6\%. De todos modos, la inversión en tierras de cultivo de sembradura era mayor por parte de estos propietarios forasteros, ya que del total de tierras de sembradura eran suyas el 41,9\% del total, frente al 31,1\% del viñedo. Como se ve, aún estaba lejos el auge por el viñedo que se vive en la actualidad, y que se refleja en la existencia de 459 Ha de viñedo frente a las 1.005,58 Ha de otros cultivos, entre ellos las $662,04 \mathrm{Ha}$ de cereal.

\subsection{El complemento de la ganadería: de los animales de labranza a la producción láctea y cárnica}

Además de la agricultura, la otra actividad que conformaba la economía agraria castellana a mediados del siglo XVIII era la ganadería. La información de las respuestas a las preguntas 18 a 20 recoge datos acerca de la pertenencia de diferentes animales que dejaban utilidad a los vecinos de Cubillas. Así, la pregunta 20 señala cada tipo de ganado existente en el pueblo, a saber, «...ganado mular, caballar, bueyes, vacas, jumentos y jumentas», así como ganado ovino.

13 Estos rendimientos del cereal eran inferiores a los ya malos datos consignados en la cercana Tierra de Campos (Hernández y CuBERo, 1987: 413, nota 50). 
Además de señalar la existencia de estos tipos de ganado, también hará relación de la utilidad que estiman a cada animal, bien por su trabajo, bien por su leche, carne o lana.

Tanto las Respuestas Generales, como el Libro de Haciendas y los Estados Generales, nos aportan información acerca del número de animales existentes, aunque con alguna mínima variación entre unos y otros documentos. Por lo que respecta a los animales dedicados a la labranza, el Libro de Haciendas señala la existencia de 7 mulas, 1 macho, 1 yegua de labranza y 8 bueyes. Esta presencia importante de bueyes indica que existían pastos suficientes en la localidad para alimentar a estos animales, premisa que a mediados del siglo XVIII ya no se cumplía en muchos pueblos del interior de Castilla, bien por la falta de tierras dedicadas a pasto, es decir, que habían sido roturadas para convertirlas en tierras de cultivo, bien porque esos pastos se agotasen rápidamente debido al clima. Como advertimos en el apartado dedicado a la agricultura y a los distintos tipos de tierras existentes, una parte muy importante de las tierras del Valle de Trigueros pertenecientes a Cubillas estaban formadas por prados, en concreto los de la Puentecilla de Salguero (16,95 Ha), las Vegas y los Huertos $(8 \mathrm{Ha})$ y el de Cespedal (1,5 Ha), amén de contar también para pasto con una ribera denominada de Vegalatorre $(43,5 \mathrm{Ha})$.

También había 3 yeguas para montar, 2 potros y 21 jumentos que servían para el acarreo de productos y personas a pequeñas distancias. Igualmente indican la existencia de un palomar, que aportaba a su dueño tanto palominos como estiércol, y 7 cerdos para cría, ya que los destinados al consumo doméstico estaban exentos de tributar.

Otro importante subsector dentro del ganadero es el referente al ganado ovino y caprino. El Libro de Haciendas muestra la existencia de 489 ovejas de cría, 142 borras de un año (es decir, corderas entre un año y dos), 189 borros, 143 carneros y 144 corderos añales (menores de un año), sumando todos ellos 1.107 cabezas ovinas, si bien hay que recordar que no disponemos de los datos referentes al estamento eclesiástico. Estas cifras varían un tanto al compararlas con los Estados Generales, ya que aquí dentro de los vecinos seglares de Cubillas aparecen 927 ovejas sin diferenciar edades. Además, aparecen dentro de los bienes del clero patrimonial de la localidad 378 ovejas, lo que haría un total de 1.315 cabezas de ganado ovino churro que en su totalidad pastaban en el término municipal de Cubillas, ya que expresamente señalan que ningún vecino tenía cabaña fuera de él.

También las Respuestas Generales muestran la presencia de 4 colmenares, que aportaban miel y cera, si bien no cuantifican las colmenas o los pies de colmena existentes (LEMEUNIER, 2011). El Libro de Haciendas, que incluye la relación de cada vecino y forastero con bienes en Cubillas, amplía su número a seis, perteneciendo dos de ellos a forasteros. Finalmente, los Estados Generales aclaran que el número de colmenas es de 22, si bien no especifica el número de colmenares existentes. 


\subsection{El resto de la actividad económica: el reducido papel del sector secundario y del terciario}

Como corresponde a una localidad del interior de Castilla que basaba su economía en la agricultura, el $80,6 \%$ de los vecinos estaban integrados en el sector primario, el 12,9 en el secundario y el 6,5 en el terciario. ${ }^{14} i$ Cuáles eran esas otras ocupaciones más allá de las agrarias? Obviando a los 16 jornaleros, 4 labradores, 1 guarda del ganado mayor, 3 pastores y 1 panadero que configuraban el sector primario, el Libro de Cabezas de Casa señala la existencia de 1 herrero, 1 tablajero o carnicero y 2 zapateros como integrantes del sector secundario, así como 1 cirujano sangrador y 1 sacristán, únicos exponentes del sector servicios. Como se ve, lo mínimo e imprescindible, por lo que los vecinos de Cubillas dependerían en muchas ocasiones para avituallarse de otros productos o servicios de localidades con mayor población, como Dueñas, Valladolid o Palencia. En la taberna existente estaba asegurado el suministro de vino -para aquellos vecinos que no tuviesen producción propia-, y de algún otro producto de alimentación como legumbres secas, vinagre, aceite o pescado en salazón, de ahí su denominación en la Respuestas Generales como abacería. Además de la taberna también existía una panadería, que era el lugar al que los vecinos llevaban la harina para ser transformada en pan.

De oficios mecánicos sólo se puede reseñar la existencia de un maestro zapatero de viejo (reparación de calzado) según las Respuestas Generales, y dos según el Libro de Cabezas de Casa, con una utilidad anual de 912 rs. El otro oficio manual que se consigna es el de un herrero, oficio indispensable en toda localidad rural, ya que era el encargado de poner al día los aperos de labranza, como por ejemplo las rejas para poder arar, así como atender los cascos de las caballerías. Por lo demás, destaca la ausencia de artefactos industriales ligados al uso de la energía hidráulica, ya que pese a encontrarse el término municipal limítrofe al río Pisuerga, estos aprovechamientos industriales -molinos y batanes- estaban ubicados en otras localidades próximas.

Los otros dos oficios mencionados son el de cirujano sangrador y sacristán. El primero hacía las veces de médico, al menos para una primera valoración, ya que si la situación se complicaba, tendrían que hacer llegar a algún médico titulado de otra localidad mayor. El cirujano, debido a esa labor social que tenía encomendada, la del cuidado de los vecinos del pueblo, percibía su salario anual, que era de 48 fanegas de trigo, gracias al repartimiento que se hacía entre todos los vecinos. Por lo que respecta al oficio de sacristán, y por lo tanto persona al cuidado de la parroquia de la villa encargada de ayudar en las celebraciones y atender los distintos toques de campana de la iglesia, percibía 547 rs. anuales. Según indican en las Respuestas Generales, 372 rs. de ellos los percibía del pago directo del diezmo correspondiente a la parroquia. Además de este oficio de sacristán, también ejercía el de Maestro de Primeras Letras, siendo la iglesia por tanto la que se encargaba de esta actividad así como de su salario.

Por lo demás, las Respuestas Generales muestran alguna información complementaria sobre los salarios de otras ocupaciones, así por ejemplo en el caso de los jornaleros dejan constancia de algo que es evidente por la propia idiosincrasia del oficio, y es que sólo percibían jornal el día que trabajaban, hecho

14 AMC, Libro de Cabezas de Casa de seglares. 
que no sucedía todos los días al año. Igualmente, no todas esas ocupaciones del campo estaban igual pagadas, por ello indican que había días donde el jornal era de 14 cuartos (1,22 rs.), mientras que otros, dicho jornal era de 3 rs., siempre en función de las necesidades del empleador, de la actividad a desarrollar (no es lo mismo arar, segar o vendimiar), y es de suponer que en función de la demanda de trabajadores. Para otros oficios agrarios también aporta información sobre los salarios, así, sabemos que los pastores mayorales del ganado lanar cobraban 912 rs. anuales, mientras que los rabadanes y ayudantes de estos pastores sólo ganaban 547 rs. Por último también indican las Respuestas Generales el salario que percibía el guarda del ganado mayor, que era de 554 rs. De ellos, 484 rs. los percibía del ayuntamiento en forma de 11 cargas de trigo, y los 70 rs. restantes se los pagaban los labradores de Cubillas «...por el cuidado de sus labranzas -sus animales de trabajo- en los tiempos que las sueltan al pasto».

\subsection{La riqueza medida en relación a la propiedad de la tierra}

Una de las grandes particularidades del Catastro de Ensenada es la de detallar los bienes de cada vecino susceptibles de generar utilidad económica. Gracias a ello podemos realizar una estimación acerca de los diferentes niveles de riqueza de los vecinos de cada localidad. A mediados del siglo XVIII y dentro de un sistema económico dominado por la economía agraria, el bien más preciado y codiciado era la tierra. Por ello, el primer y mejor indicador para cuantificar el nivel de riqueza de los habitantes de una localidad es el de conocer cuántas tierras poseían y explotaban.

El cuadro 3 muestra a todos los vecinos de Cubillas que eran propietarios de tierras de sembradura en el término municipal, o que declararon que llevaban en arrendamiento tierras de este tipo. En total son 17 -un $43 \%$ - los vecinos que tienen tierras, o lo que es lo mismo, más de la mitad de todos los vecinos de Cubillas no podían disponer de tierras de cultivo, por lo que o bien tenían otro oficio ajeno a la tierra -los menos-, o tan sólo podían aportar su fuerza de trabajo para desarrollarla en las explotaciones agrarias de estos propietarios. No obstante, hay que analizar con mayor detenimiento los datos que nos muestra el cuadro 3, ya que de lo contrario sólo nos quedaríamos con el dato de que algo más del 40\% de los vecinos de Cubillas tenía tierras de cultivo. Siendo esto cierto, tan sólo 2 vecinos eran propietarios de más de 50 hectáreas de tierra, es decir, podían vivir de manera holgada del cultivo del campo, y solamente 12 superaban las 10 hectáreas de tierra. Teniendo en cuenta que, como ya se ha señalado con anterioridad, el sistema de cultivo era el de año y vez, hay que interpretar los datos del cuadro sabiendo que cada año sólo podrían tener producción en la mitad de las tierras. De este modo se comprende que la mayoría de los propietarios no podían vivir en exclusiva de la producción agraria propia, y tendrían que vender su fuerza de trabajo para otros titulares de explotaciones agrarias, es decir, se convertirían en meros jornaleros. Es más, los pequeños propietarios que tenían que alternar su faceta de jornaleros con la de labradores, serían los primeros en perder su escaso patrimonio al encadenar un par de años de malas cosechas, siendo absorbido éste por aquellos que les hubiesen prestado algún capital, fundamentalmente instituciones eclesiásticas que de esta manera seguían ampliando su patrimonio (SENADOR, 1992). 
CuAdro 3

Vecinos propietarios de tierras de sembradura en Cubillas (1751)

\begin{tabular}{|c|c|c|}
\hline Tamaño de las propiedades (en Ha) & Número de Propietarios & Hectáreas \\
\hline$<50$ & 15 & 78,8 \\
\hline $51-100$ & 1 & 63 \\
\hline$>100$ & 1 & 141,7 \\
\hline
\end{tabular}

Fuente: Elaboración propia a partir del Libro de Haciendas.

Si ponemos nombre a los datos, estos revelan los dos grandes propietarios de Cubillas de Santa Marta en este momento: Tomás de Rueda (141,7 Ha) y Adriano Gil (63 Ha), quienes no por casualidad eran los dos únicos vecinos que tenían criados para las tareas de la labranza. Otro dato que muestra el poder económico de estos dos vecinos frente al resto es la posesión de animales de labranza, ya que eso era sinónimo de mantener yuntas de labor, y por ende tierras en cultivo. Tomás de Rueda poseía 5 mulas, 3 yeguas de labranza y 7 bueyes, es decir, 15 animales lo que es una potencia de tiro más que suficiente para manejar toda su extensa labranza. Por su parte el otro gran propietario, Adriano Gil, contaba con 2 mulas, 1 macho y una yegua de labranza. Por lo demás, y acorde a la distribución de la propiedad de la tierra que hemos apuntado, tan sólo dos vecinos propietarios más tenían animales de tiro: Francisco Velasco un buey, e Hipólito Núñez una yegua de labranza, es decir, ambos tenían medio par de labranza.

Si hacemos el mismo análisis para los vecinos propietarios o arrendatarios de viñedos, los datos son los que muestra el cuadro 4 . Un total de 20 vecinos de Cubillas eran propietarios de viñedos, es decir, un número más elevado que el de las tierras de sembradura, lo que probablemente esté relacionado con el hecho de que las propiedades de viñedo fuesen de una extensión más pequeña, de hecho 11 de estos propietarios lo son en una cuantía inferior a 1 hectárea, lo que indicaría una minúscula producción para el autoconsumo y, si acaso, una pequeña cantidad de producto sobrante para la venta. Probablemente esto quede sustentado por el hecho de que tan sólo haya 9 propietarios de bodegas en la localidad, teniendo todos ellos una, a excepción de los potentados Adriano Gil y Tomás de Rueda que poseen 2 o al menos tienen parte en más de una.

CuAdro 4

Vecinos Propietarios de viñedos en Cubillas (1751)

\begin{tabular}{|c|c|c|}
\hline Tamaño de las propiedades & Número de Propietarios & Hectáreas \\
\hline $0-5 \mathrm{Ha}$ & 18 & 16 \\
\hline $5-10 \mathrm{Ha}$ & 1 & 6,3 \\
\hline$+10 \mathrm{Ha}$ & 1 & 17,6 \\
\hline
\end{tabular}

Fuente: Elaboración propia a partir del Libro de Haciendas. 
El resto de propietarios de bodegas también eran propietarios de viñedos, donde transformarían el mosto de sus uvas en vino, previo paso por alguno de los seis lagares existentes en 1751. Además de los propietarios vecinos de Cubillas, también encontramos 7 forasteros que tienen una bodega o partes de alguna bodega en la localidad, siendo éstas generalmente más pequeñas, salvo la de Sebastián de Cañas, vecino de Dueñas, quien posee una bodega entera de su propiedad con capacidad para 408 cántaros.

Alguna diferencia sustancial sí que se observa respecto a lo señalado para las tierras de sembradura, así, la aparición de tan sólo un vecino arrendatario de viñedo, Santos Ortega, con 2,1 hectáreas de buena y mediana calidad, lo que indica que las pequeñas parcelas de viñedo eran en su mayoría explotadas directamente por sus propietarios, configurando por tanto un paisaje de pequeñas manchas verdes y marrones sobre un manto homogéneo de cereal. Esto estaría justificado por dos situaciones: en primer lugar, la de proteger el cultivo del viñedo, ya que una explotación deficiente a la larga redundaría en una menor producción e incluso la pérdida del viñedo; y en segundo lugar, a que ya desde la segunda mitad del siglo XVII la oferta de vino para la cercana ciudad de Palencia -y no hay que pensar que para Valladolid fuese distinto- comenzase a descender, lo que permitía aumentar los precios del vino, motivo éste que alentó a algunos agricultores de la zona a volver a plantar vides, ya que su producción tenía una salida asegurada a pesar también del incremento generalizado del precio del trigo.

Como se puede ver por los datos aportados respecto a la propiedad de las tierras de cultivo, había dos vecinos considerados hacendados con suficientes tierras y viñas para disponer de una labranza rica y acomodada, plasmada sobre el mapa local en un latifundio, acompañada de un importante número de trabajadores y de animales de labranza. Por el contrario, el resto de propietarios difícilmente podrían mantenerse con esas pequeñas labranzas, estando por tanto en riesgo de caer ante cualquier crisis de subsistencia que surgiese como consecuencia de una crisis agraria. Estas pequeñas propiedades, diseminadas por todo el terrazgo municipal, condicionaban el paisaje haciéndolo discontinuo y tremendamente parcelado, hecho que incidía en sus escasos rendimientos.

Además de la agricultura, el otro pilar de la economía agraria era la ganadería ovina. Los datos son concluyentes: tan sólo había 4 propietarios de ganado ovino en la localidad. De ellos dos eran modestos propietarios con 26 y 4 ovejas respectivamente, mientras que de nuevo vuelven a aparecer como los mayores propietarios de ganado ovino los mayores propietarios de tierra: Adriano Gil con 448 cabezas ovinas, y Tomás de Rueda con 636. El hecho de disponer de recursos para contratar pastores -el primero dos y el segundo tres-, y además el hecho de contar con tierras en las que poder pastar, propiciaban este número de cabezas de ganado. De hecho, estos dos propietarios llevaban en arrendamiento tres prados y la ribera propiedad del concejo por 1.623 rs. anuales, disponiendo de una extensión de 68,6 hectáreas en las que poder pastar sus ganados. Además, la mitad de las tierras de su propiedad anualmente estaban de barbecho, por lo que podían entrar las ovejas a pastar en ellas, al tiempo que abonaban dicho terreno para el cultivo del siguiente año.

Del resto de ganado el más numeroso eran los jumentos, cuya propiedad recaía en 12 vecinos de Cubillas. Estos animales, considerados como «el ganado de los pobres» (MARCOS, 1985), eran de una gran utilidad gracias a su versatilidad, pues además de llevar pequeñas cargas, también servían para transportar a 
las personas, y en algunos casos ayudar en determinadas tareas agrícolas. Por lo demás, llama la atención el escaso número de cerdos declarados -7-, si bien éstos eran exclusivamente los dedicados a la cría para su venta y obtención de beneficio económico, no los criados en las casas para después ser sacrificados para el sustento familiar.

Como se ha podido ver aunque de forma muy sucinta, la riqueza agraria dentro de los vecinos de Cubillas estaba concentrada en muy pocas manos. Mientras estos dos grandes propietarios disfrutaban de todos estos bienes, una minoría se encontraba con escasos recursos, pero intentando depender de ellos mismos, y una mayoría de la población, como sucedía en el resto de Castilla, malvivía a expensas de jornales escasos e intermitentes.

\section{CONCLUSIONES}

Tres eran los objetivos que se planteaban al inicio de este trabajo: evaluar la viabilidad de efectuar estudios geohistóricos para conocer la realidad socioeconómica de las localidades que integraban la corona de Castilla a mediados del siglo XVIII; explorar la viabilidad del Catastro de Ensenada como fuente válida para elaborar estudios geohistóricos; y diseñar una estrategia para aprovechar todos los recursos documentales que ofrece el Catastro. Respecto al primer objetivo, se ha demostrado que ya desde los pioneros estudios de mediados del siglo xx que utilizaron el Catastro para conocer aspectos de la realidad económica castellana del siglo XVIII, ésta es una fuente viable para obtener ese conocimiento. La información del Catastro permite realizar una radiografía de la sociedad, la economía y el paisaje de un pueblo castellano en este periodo histórico. Las páginas de este documento constituyen una fuente esencial para comprender e interpretar la geografía y conocer la organización del territorio. Así pues, gracias al marqués de la Ensenada podemos saber la distribución de las propiedades, rústicas y urbanas, de una localidad. También es interesante la información que se recoge de la actividad agraria, principal soporte económico de la población y, en especial, de los sistemas de cultivo que se empleaban en el campo, de los tipos de cultivos y sus producciones, la estructura del parcelario, o el valor económico generado de las explotaciones. Todo ello son piezas que al unirlas permiten configurar el paisaje típico de Castilla, de componente agrario, y que no difiere tanto del existente en la realidad. Junto a la información agraria hay que remarcar también la relativa a los otros sectores económicos, secundario y terciario, y que debido a la poca población existente en Cubillas eran muy poco representativos, especialmente en el mundo rural. El detallado estudio demográfico recogido en el catastro contabilizando a todos los habitantes, sus edades, estado civil y oficios, permite conocer con nombres y apellidos a todos sus vecinos. En definitiva, numerosas variables geográficas que hacen de este documento una fuente geohistórica esencial para explicar e interpretar la economía, la sociedad y el paisaje castellano. Además, una de sus principales virtudes es la de poder cartografiar el territorio, lo que permite establecer pertinentes comparaciones con el presente en lo que respecta a la utilización de recursos naturales como pueden ser la tierra o los recursos hídricos. 
Del mismo modo se ha podido confirmar cómo el Catastro es una fuente documental adecuada para efectuar estos estudios geohistóricos habida cuenta de su universalidad para la corona de Castilla, y sobre todo a su homogeneidad documental, lo que permite la seriación de su estudio. De esta forma evitamos los aspectos más locales que podían afectar a la confección de esta documentación, ya que ésta fue diseñada y controlada en todo momento por la Administración Central.

Por último, como se ha demostrado en los diferentes epígrafes del trabajo, se ha establecido una metodología de trabajo por la que todos los estratos documentales de la operación catastral han sido utilizados, integrando de esta forma todos los datos disponibles. Gracias a esta metodología, que puede ser utilizada para cualquier otra localidad de la corona de Castilla, podemos tener la seguridad de que conocemos todo lo relevante referido a la economía de mediados del siglo XVIII, así como disponer de recursos suficientes para poder establecer comparaciones con la situación actual en cuanto a la producción agraria, la utilización de la tierras y la evolución del paisaje. La situación de estos pequeños municipios no difiere demasiado a la existente en la realidad, es decir, pueblos pequeños, que pierden población, cada vez más envejecidos, con una base económica centrada en la actividad agraria y una concentración de las explotaciones en cada vez menos manos.

\section{REFERENCIAS}

BenNAsSAR, B. (1967): Valladolid au siècle d'or: une ville de Castille et sa campagne au XVIe siècle, Mouton, Paris.

Béthencourt MAssieu, A. (2004): «Fiscalidad y franquicias en Canarias durante el Antiguo Régimen», en XV Coloquio de historia canario-americana, Cabildo Insular de Gran Canaria, Las Palmas de Gran Canaria: 1714-1730.

BLoch, M. (1952): Introducción a la historia, Fondo de Cultura Económica, México.

Braudel, F. (1953): El Mediterráneo y el mundo mediterráneo en la época de Felipe II, Fondo de Cultura Económica, México.

BRAUdel, F. (1968): La historia y las ciencias sociales, Alianza, Madrid.

Brumont, F. (1977): La Bureba a l'époque de Philippe II, Arno Press, New York.

CABo Alonso, Á. (1955): «La Armuña y su evolución económica», Estudios Geográficos, 16 (58): 73-136.

Cabo Alonso, Á. (1956): «El colectivismo agrario en Tierra de Sayago», Estudios Geográficos, 17 (65): 593-658.

Camarero Bullón, C. (1989): Burgos y el Catastro de Ensenada, Caja de Ahorros Municipal de Burgos, Burgos.

Camarero Bullón, C. (1993): El debate de la Única Contribución: catastrar las Castillas, 1749, Tabapress, Madrid.

Camarero Bullón, C. (1998): «La cartografía en el Catastro de Ensenada», Estudios Geográficos, 59: 245-283.

Camarero Bullón, C. (2002a): «El Catastro de Ensenada, 1749-1759: diez años de intenso trabajo y 80.000 volúmenes escritos», CT Catastro, 46: 61-88.

Camarero Bullón, C. (2002b): «Averiguarlo todo de todos: el Catastro de Ensenada», Estudios Geográficos, 63 (248-249), 493-531. https://doi. 
org/10.3989/egeogr.2002.i248-249.236

CAMARERO Bullón, C. (2006): «Vasallos y pueblos castellanos ante una averiguación más allá de lo fiscal: el Catastro de Ensenada, 1749-1756», en El Catastro de Ensenada. Magna averiguación fiscal para alivio de los vasallos y mejor conocimiento de los Reinos: 1749-1756, Ministerio de Economía y Hacienda, Madrid: 113187.

Camarero Bullón, C.; García JuAn, L. (2018): «Geografía histórica de los espacios reales: Alóndiga, Aceca y Barciles, despoblados del rey en la vega del Tajo», Estudios Geográficos, 79: 209-235. https:/ / doi.org/10.3989/estgeogr.201809

Camarero Bullón, C.; Aguilar Cuesta, A.I.; García Juan, L. (2018): «El Vecindario y el Censo de Ensenada: el final de una época y el inicio de los recuentos poblacionales», CT Catastro, 93: 31-64.

Censo de la Corona de Castilla 1591 (1986). Instituto Nacional de Estadística, Madrid.

Crespo Redondo, J. (1968): El paisaje agrario en los Arribes del Duero, Instituto Juan Sebastián Elcano, Madrid.

Cubero Garrote, J.; Hernández García, R. (2017): «La tierra y el hombre en la Tierra de Campos vallisoletana a mediados del siglo XVIII», Investigaciones históricas: Época moderna y contemporánea, 37: 381-420. https://doi.org/10.24197/ ihemc.37.2017.381-420

FEbVRE, L. (1970): Combates por la historia, Ariel, Barcelona.

Fernández Portela, J. (2018): «Historia, paisaje e identidad de la vid y el vino en la comarca vitivinícola de Cigales», en El Catastro de Ensenada. Magna averiguación fiscal para alivio de los vasallos y mejor conocimiento de los reinos (1749-1756): Comarca vitivinícola de Cigales, 1751-1752, Dirección General del Catastro, Madrid: 52-73.

García Fernández, J. (1963): Aspectos del paisaje agrario de Castilla la Vieja, Universidad de Valladolid, Valladolid.

García Fernández, J. (1986): El clima en Castilla y León, Ámbito, Valladolid.

García Juan, L., Camarero Bullón, C. y Fernández Portela, J. (2017): «Estudiar el pasado para comprender el paisaje del presente: La Acequilla (Azuqueca de Henares, Guadalajara)», en Naturaleza, territorio y ciudad en un mundo global, Asociación de Geógrafos Españoles, Madrid: 1933-1942.

García Sanz, Á. (1986): Desarrollo y crisis del Antiguo Régimen en Castilla la Vieja: economía y sociedad en tierras de Segovia de 1500 a 1814, Akal, Madrid.

Gómez UrdáÑez, J.L. (2017): El marqués de la Ensenada: el secretario de todo, Punto de vista, Madrid.

Hernández García, R. (2018): «La campiña del Pisuerga en la época del Catastro de la Ensenada», en El Catastro de Ensenada. Magna averiguación fiscal para alivio de los vasallos y mejor conocimiento de los reinos (1749-1756): Comarca vitivinícola de Cigales, 1751-1752, Dirección General del Catastro, Madrid: 74-103.

Hernández García, R.; Cubero Garrote, J. (2017): La Tierra de Campos de Valladolid en el siglo XVIII. Estudio y transcripción de las Respuestas Generales del Catastro de la Ensenada, Diputación de Valladolid, Madrid.

Huetz DE Lemps, A. (1967): Vignobles et vins du nord-ouest de l'Espagne, Institut de Géographie, Bordeaux.

Jovellanos, G.M. de. (1994): Obras completas. 6. Diario (cuadernos I a V hasta 30 de agosto de 1794), Instituto Feijoo de Estudios del siglo XVIII, Oviedo.

LADURIE, L. R. (1973): Le Territoire de l'historien, Gallimard, Paris.

Lemeunier, G. (2011): «La apicultura en Francia y España entre los siglos XVIII y 
El Catastro de Ensenada, una fuente geohistórica para el estudio del territorio

XIX», Historia agraria: Revista de agricultura e historia rural, 54: 17-40.

López Gómez, A. y Manso Porto, C. (2006): Cartografía del siglo XVIII. Tomás López en la Real Academia de la Historia, Real Academia de la Historia y Fundación Caja Madrid, Madrid.

López RuIz, J.A. (2007): La sociedad rural y el problema de la despoblación: perfiles sociales y actitudes ante la despoblación en Castilla y León, Tesis Doctoral, Universidad Pontificia de Salamanca, Salamanca.

Marcos Martín, A. (1985): Economía, sociedad, pobreza en Castilla. Palencia, 15001814, Diputación Provincial de Palencia, Palencia.

Matilla Tascón, A. (1947): La Única contribución y el Catastro del Marqués de la Ensenada. Ministerio de Hacienda, Madrid.

MolinA DE LA TORRE, I. (2018): «La despoblación en España: un análisis de la situación», Informe Comunidades Autónomas, 2018: 66-87.

Molinero Hernando, F. (2012): «Las intensas transformaciones del mundo rural castellano y leonés: la marcha hacia el cuarto paradigma de desarrollo rural», en Población y poblamiento en Castilla y León, Consejo Económico y Social de Castilla y León, Valladolid: 559-636.

Muñoz NAvarro, D. (2010): «El Catastro de Ensenada como fuente para la Historia Agraria: paisaje y actividad agropecuaria en la villa de Requena a mediados del siglo XVIII», CT: Catastro, 70: 51-69.

Nogué I Font, J.; SAN Eugenio Vela, J. (2017): «La contribución del paisaje visual en la generación de marcas territoriales», Boletín de la Asociación de Geógrafos Españoles, 74: 143-160. https://doi.org/10.21138/bage.2448

Olmo, P. Del; Portero, J.M. (1982): Mapa Geológico de España. E. 1/50.000. Cigales. 343, Ministerio de Industria, Madrid.

Orella UNZUE, J.L. (1995): «Geohistoria», Lurralde, 18: 7-20.

Ortega Valcárcel, J. (1969): «La evolución del paisaje agrario del Valle de Mena (Burgos)», Estudios Geográficos, 30 (114): 107-164.

Peña SÁnchez, M. (1987): Tierra de Campos: la integración de un espacio rural en la economía capitalista, Universidad de Valladolid, Valladolid.

Pillet Capderón, F. (2007): «Catastro y propiedad rústica y urbana (1750-2005) y su relación actual con las comunidades autónomas: aplicación a Castilla-La Mancha», Boletín de la Asociación de Geógrafos Españoles, 45: 213-232.

Rodríguez Villa, A. (1878): Don Zenón de Somodevilla, Marqués de la Ensenada. Ensayo biográfico formado con documentos en su mayor parte originales, inéditos y desconocidos, Librería de M. Murillo, Madrid.

SENADOR GómEZ, J. (1992): Castilla en escombros: las leyes, las tierras, el trigo y el hambre, Ámbito, Valladolid.

Serrano, E.; Pellitero, R.; Otero, M. (2010): «Huellas pleistocenas de frío intenso en la Cuenca del Duero: cuñas de arena relictas en las terrazas del Pisuerga», en XI Reunión de la Sociedad Española de Geomorfología, Solsona: 417-420.

Vallina Rodríguez, A. y KonyushikHinA, N. (2017): «Los interrogatorios de los Catastros españoles de la Edad Moderna. Fuentes geohistóricas para conocer los paisajes y las sociedades», CT Catastro, 91: 39-63.

Vidal DomíngueZ, M.J. (2018): «El paisaje urbano madrileño de mediados de los siglos XVIII y xIX: análisis de casos», CT: Catastro, 94: 35-70.

VIDAL DE LA BLANCHE, P. (1913): «Des caractères distinctifs de la géographie», Annales de Géographie, 22 (124): 289-299. 